\title{
Efeito da solarização e biofumigação, durante o outono, na incidência de murcha-bacteriana e produtividade da batata
}

\author{
Mírian Josefina Baptista; Carlos Alberto Lopes; Ronessa B de Souza; Ossami Furumoto \\ ${ }^{1}$ Embrapa Hortaliças, C. Postal 218, 70359-970 Brasília-DF; E-mail: mirian@cnph.embrapa.br
}

\section{RESUMO}

A murcha-bacteriana causada por Ralstonia solanacearum é uma das principais doenças da cultura da batata. A solarização tem sido estudada como opção para a desinfestação do solo e tem potencial para o controle da murcha bacteriana. A técnica é indicada para uso nas estações quentes do ano pois depende de condições climáticas adequadas. Devido ao período de plantio de determinadas culturas, é interessante avaliar o uso da solarização em outras épocas do ano e associada a outras técnicas para garantir sua eficiência. A biofumigação é a desinfestação do solo através da adição de matéria orgânica que, durante sua decomposição, libera substâncias tóxicas aos fitopatógenos. Neste trabalho avaliou-se durante o outono (maio a junho) os efeitos da adição de cama de aves (biofumigação) e da solarização na incidência natural da murchabacteriana e na produtividade da batata, através dos tratamentos: adição de cama de aves (20 t/ha), uréia (100 kg/ha), aplicação de brometo de metila e solo sem tratamento (testemunha), todos solarizados ou não solarizados. Avaliou-se a produção de tubérculos totais e comerciais e, a partir da incidência de murchabacteriana, foi feito o cálculo da área abaixo da curva de progresso da doença (AACPD). Na área infestada, apenas o uso do brometo de metila proporcionou reduções significativas na incidência da murcha-bacteriana. No entanto, a aplicação de brometo de metila e a adição de cama de aves em associação com a solarização possibilitaram produção significativamente maior de tubérculos de batata em relação à testemunha. Os efeitos da solarização associada à biofumigação com cama de aves sobre a produtividade da batata em área infestada com $R$. solanacearum devem ser melhor investigados.

Palavras Chave: Solanum tuberosum, Ralstonia solanacearum, controle físico, matéria orgânica, fitopatógenos do solo, manejo integrado.

\begin{abstract}
Effect of soil solarization and biofumigation during autumn on bacterial wilt incidence and potato yield

Bacterial wilt caused by Ralstonia solanacearum is one of the most important diseases of the potato. Soil solarization has been studied as an option for soilborne disease control with potential for bacterial wilt control. The method should be used during the hot season and depends on weather conditions. It is important to evaluate this method in other seasons, associated with other control methods. Biofumigation is the soil disinfestation through organic residue amendment. During decomposition, these residues release toxic substances to soilborne pathogens. An experiment was carried out during the autumn (May to June), to evaluate the effect of amendment with chicken litter (biofumigation) and solarization on bacterial wilt incidence and yield of potato plants. The treatments were chicken litter amendment (20 t/ha), urea (100 kg/ha), methyl bromide application and no amendment (control), all treatments with or without solarization. Weekly evaluations of bacterial wilt incidence permitted to obtain the area under the disease progress curve for each treatment. In infested areas, only methil bromide application reduced bacterial wilt incidence, but methyl bromide application and chicken litter amendment combined with soil solarization allowed higher potato tuber production. The effect of soil solarization associated with biofumigation on potato yield in $R$. solanacearuminfested areas needs to be better investigated.
\end{abstract}

Keywords: Solanum tuberosum, Ralstonia solanacearum, physical control, organic matter, soilborne phytopathogens, integrated management.

\section{(Recebido para publicação em 4 de maio de 2005; aceito em 10 de fevereiro de 2006)}

A murcha-bacteriana causada por Ralstonia solanacearum é uma das principais doenças da cultura da batata (Lopes \& Quezado-Soares, 2000). A ocorrência de infecção latente (sem sintomas visíveis) facilita sua introdução através de tubérculos contaminados, em áreas livres do patógeno. A doença é responsável por redução da produtividade da batata e condenação de campos de batata semente, sendo um dos principais entraves à produção nacional. A bactéria infecta várias plantas daninhas que mantêm as populações do patógeno no solo dificultando o controle da doença no campo (Lopes \& Quezado-Soares, 2000).

Recentemente, o enfoque em questões ambientais e novos sistemas de pro- dução, como agricultura orgânica, tem estimulado as pesquisas voltadas a medidas de controle alternativas, visando estabelecer o controle integrado dos fitopatógenos do solo.

A solarização é um método de desinfestação do solo que consiste na cobertura do solo úmido com polietileno transparente, na estação quente do ano, antes do plantio. Esta cobertura provoca um efeito estufa que eleva a temperatura do solo e causa a morte ou enfraquecimento dos propágulos de microrganismos fitopatogênicos. Assim, os efeitos no solo são menos drásticos, as temperaturas são mais baixas que as alcançadas nos tratamentos com vapor, não produz efeitos fitotóxicos e não cria o vácuo biológico no solo que favorece a reinfestação por organismos patogênicos. Muitos microrganismos saprófitas sobrevivem ao tratamento de solarização, o que favorece o controle biológico e a obtenção de características supressivas pelo solo (Souza, 1994). No Brasil, diversos trabalhos têm demonstrado a eficiência da solarização (Ghini et al. 2002; May de Mio et al., 2002; Sinigaglia et al., 2001; Ghini et al., 2003). Em batata, Elad et al. (1980) verificaram efeito significativo da solarização no controle de Rhizoctonia solani e Verticillium dahliae e Davis \& Sorensen (1986) verificaram o controle de Streptomyces scabies, $R$. solani e $V$. dahliae. São poucos os trabalhos rela- 
cionados ao controle de bactérias fitopatogênicas pela solarização. As características de sobrevivência de $R$. solanacearum no solo tornam difícil seu controle e o maior número de resultados da solarização envolve o controle de fungos fitopatogênicos habitantes do solo e de plantas daninhas. Recentemente, Schonfeld et al. (2003) estudaram os efeitos da adição de composto orgânico e da solarização na sobrevivência de $R$. solanacearum biovar 2 no solo. A solarização do solo, sem a adição de composto orgânico, não afetou significativamente a sobrevivência da bactéria, mas a adição de composto juntamente com a solarização reduziu a população bacteriana e a incidência da doença.

A adição de resíduos orgânicos de origem animal ou vegetal ao solo para o controle de fitopatógenos é uma opção de uso em conjunto com a solarização. A decomposição de resíduos orgânicos ricos em nitrogênio, como o esterco animal, leva à liberação de amônia e ácido nitroso no solo, que são tóxicos a muitos fitopatógenos (Lazarovits, 2001), produzindo um efeito de fumigação biológica (biofumigação). A grande utilidade da adição de matéria orgânica para o controle de fitopatógenos está na combinação dos dois métodos que atuam sinergisticamente para obter controle de doenças em locais ou situações onde apenas um deles seria ineficiente (Stapleton, 2000).

Michel \& Mew (1998) estudaram o efeito da aplicação de uréia ao solo e verificaram redução da população de $R$. solanacearum, proporcional às concentrações de nitrito no solo. Coca (2001) aplicou esterco de galinha e sulfato de amônio no solo e obteve redução da incidência da murcha-bacteriana e aumento da produção das cultivares suscetíveis Bintje e Monalisa. A possibilidade de reduzir a população de $R$. solanacearum no solo utilizando estes métodos, como estratégias de manejo integrado da doença, pode aumentar as perspectivas de controle da murcha-bacteriana. Este trabalho teve como objetivo avaliar o efeito da solarização e da biofumigação sobre a incidência de murcha-bacteriana e produtividade da batata em área infestada com $R$. solanacearum.

\section{MATERIAL E MÉTODOS}

O experimento foi conduzido em área (20 x 30 m) naturalmente infestada com a raça 1 , biovar 1 de $R$. solanacearum, loca- lizada no campo experimental da Embrapa Hortaliças em Brasília. O solo foi arado até $30 \mathrm{~cm}$ de profundidade, usando subsolador e enxada rotativa. $\mathrm{O}$ experimento foi instalado em blocos ao acaso com parcelas subdivididas, com 4 blocos de $6 \times 20 \mathrm{~m}$ com uma parcela solarizada e uma não solarizada. Nas parcela foram instalados os tratamentos: adição de uréia (100 kg/ha), adição de cama de aves (20 t/ha), testemunha e aplicação de brometo de metila (600 $\mathrm{cm}^{3}$ por parcela). A uréia e cama de aves foram aplicados ao solo antes da colocação do plástico para solarização e em seguida toda área foi irrigada até a capacidade de campo. No dia seguinte, as parcelas a serem solarizadas foram cobertas com plástico de polietileno transparente de 75 $\mathrm{mm}$ de espessura. As bordas do plástico foram enterradas a $20 \mathrm{~cm}$ de profundidade, tomando-se o cuidado de evitar o acúmulo de ar sob o plástico. O plástico permaneceu no solo por 63 dias durante os meses de maio e junho. A aplicação do brometo de metila foi feita após a solarização. A época de solarização foi escolhida em função do período tradicional de plantio da batata e regime de chuvas na região do DF (abril a julho). Durante este período as temperaturas do solo foram monitoradas com termômetro, diariamente, entre 14:00 e 15:00 horas. Foram registradas as temperaturas a 5; 10 e $20 \mathrm{~cm}$ de profundidade em todas as unidades experimentais. Após a solarização a área foi preparada para o plantio com correção do $\mathrm{pH}$ e adubação recomendada para a batata, igualmente em todas as parcelas, de acordo com Fontes (1999). Foi plantada a cultivar 'Monalisa', e durante todo o período de desenvolvimento da cultura foi feito o monitoramento para verificar a incidência de doenças causadas por fitopatógenos do solo, em especial, $R$. solanacearum. Foram avaliadas oito plantas em cada tratamento semanalmente durante a condução da cultura. A incidência de murcha-bacteriana foi calculada pela porcentagem de plantas murchas. Os dados de nove avaliações foram utilizados no cálculo da área abaixo da curva de progresso da doença (AACPD) para cada tratamento. No final do cultivo (90 dias após o plantio) foi determinada a produção total e comercial (tubérculos acima de $45 \mathrm{~mm}$ de diâmetro) de tubérculos. Foi avaliada também a ocorrência de defeitos fisiológicos como "embonecamento", rachaduras, "coração oco" e "mancha chocolate" em 10 tubérculos coletados ao acaso em cada tratamento.

\section{RESULTADOS E DISCUSSÃO}

As temperaturas alcançadas no solo solarizado foram mais baixas que aquelas alcançadas com solarização entre agosto e setembro na região do DF (Baptista et al., 2004) devido às temperaturas ambientais mais baixas e menores períodos de insolação nesta época do ano (Embrapa, 2005). Durante o mês de maio as temperaturas ambientais médias diárias foram $27,8^{\circ} \mathrm{C}$ (máxima) e 15,9² $\mathrm{C}$ (mínima), com 7,2 horas de insolação média diária. No mês de junho as temperaturas médias diárias foram $26,1^{\circ} \mathrm{C}$ (máxima) e $13,5^{\circ} \mathrm{C}$ (mínima), com 8,4 horas de insolação média diária (Embrapa, 2005). Foram obtidas temperaturas médias no solo solarizado de $41^{\circ} \mathrm{C}$, $35,8^{\circ} \mathrm{Ce} 30,8^{\circ} \mathrm{C}$ a $5 ; 10$ e $20 \mathrm{~cm}$ de profundidade, respectivamente. No solo não solarizado as temperaturas médias foram $32,4^{\circ} \mathrm{C}, 28,1^{\circ} \mathrm{C}$ e $25,3^{\circ} \mathrm{C}$ a $5 ; 10$ e $20 \mathrm{~cm}$ de profundidade, respectivamente. Nos meses de agosto e setembro, nesta região, as temperaturas do solo chegam à médias de $45^{\circ} \mathrm{C}$, $40,5^{\circ} \mathrm{C} \mathrm{e} 34,6^{\circ} \mathrm{C}$ a $5 ; 10$ e $20 \mathrm{~cm}$ de profundidade, respectivamente (Baptista et al., 2004). Embora as temperaturas do solo observadas no presente trabalho tenham sido mais baixas, verificou-se o aumento da temperatura em relação às parcelas não solarizadas, o que justificou a avaliação do efeito da solarização aliada à biofumigação no controle da murcha-bacteriana. Este aumento de temperatura pode exercer efeitos sobre a microbiota do solo e/ou potencializar os efeitos da biofumigação. As temperaturas alcançadas neste experimento, no entanto, não foram suficientes para impedir o crescimento de plantas daninhas sob o plástico e, 30 dias após a instalação, foi necessário retirá-lo para fazer a capina manual de plantas daninhas, sendo recolocado em seguida.

A solarização do solo é uma técnica dependente do clima, sendo recomendada em períodos do ano com maiores temperaturas e horas de insolação diária (Katan, 1981). O uso da solarização durante meses frios do ano e com baixa radiação solar não é recomendado. No entanto, seu uso em conjunto com outras técnicas pode ser avaliado para verificar a possibilidade de controle de fitopatógenos do solo mesmo nestes períodos, ampliando sua aplicabilidade (Stapleton, 2000).

$\mathrm{O}$ experimento foi instalado em área altamente infestada, onde foram atingi- 
dos níveis de incidência da murchabacteriana próximos de $100 \%$ em algumas unidades experimentais. Embora tenha-se verificado uma tendência de redução da quantidade de doença em função da solarização, apenas o tratamento com brometo de metila apresentou redução significativa ( $5 \%$ de probabilidade) na área abaixo da curva de progresso da doença (AACPD) (Figura 1). No entanto, o uso do brometo de metila como agente fumigante do solo, apresenta sérias restrições devido a seu alto custo, elevada toxidez, efeito biocida no solo (que pode favorecer a rápida reinfestação por patógenos) e principalmente aos danos que causa à camada de ozônio (Ghini, 2001). Estes problemas levaram à proibição de seu uso na agricultura a partir do ano de 2006 (MAPA, 2002). Apesar de não ter sido verificada diferença significativa naAACPD entre os outros tratamentos, verificou-se efeito significativo sobre a produção. Não foram observados defeitos fisiológicos nos tubérculos nos tratamentos utilizados. Considerando-se o peso e tamanho dos tubérculos (Tabela 1), apenas o uso do brometo de metila e a solarização combinada à adição de cama de aves promoveram aumento significativo da produção. Entre os outros tratamentos, solarizados ou não solarizados, não houve diferença significativa. A solarização isoladamente não apresentou efeito sobre a produção e não foi suficiente para o controle da doença quando feita nesta época do ano, evidenciando a necessidade de realização do tratamento no verão e/ou a associação com outras técnicas para que se obtenha o controle da murcha-bacteriana. A solarização, o uso da uréia e a adição de cama de aves isoladamente também não produziram efeitos significativos (Tabela 1). Coca (2001) verificou redução significativa (cerca de 70\%) da incidência de murcha-bacteriana em batata no campo com a adição de 10 t/ha de cama de aves. $\mathrm{O}$ experimento foi realizado também no período de maio a julho no DF e a diferença nos resultados, possivelmente, é devida à alta infestação da área utilizada neste experimento.

O efeito significativo da solarização associada à adição da cama de aves sobre a produção não foi seguido por alterações significativas na quantidade final de doença (AACPD) (Figura 1). Neste experimento a murcha-bacteriana causou danos bastante intensos na cultura e a testemunha não solarizada apresentou uma produção de pouco mais de 3 toneladas por hectare (Ta-

Tabela 1. Produção total e comercial de tubérculos de batata em solo infestado com Ralstonia solanacearum, tratado com uréia, cama de aves e brometo de metila, solarizado ou não solarizado $^{1,2}$. Brasília, Embrapa Hortaliças, 2004.

\begin{tabular}{|c|c|c|c|}
\hline Solarização & Tratamento do solo & 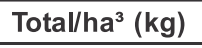 & Comercial/ha (kg) \\
\hline \multirow[t]{4}{*}{ Solarizado } & Testemunha & $4273,24 \quad b$ & 3341,55 \\
\hline & Uréia & $5631,47 \quad b$ & $4974,59 \quad b$ \\
\hline & Cama & $15208,91 \mathrm{a}$ & 13863,29 a \\
\hline & Brometo & $15847,28 \mathrm{a}$ & 14015,77 a \\
\hline \multirow[t]{4}{*}{ Não solar. } & Testemunha & $3196,88 \quad b$ & 2654,83 \\
\hline & Uréia & $1679,00 \quad b$ & 1300,74 \\
\hline & Cama & $1576,03 \quad b$ & 917,21 \\
\hline & Brometo & 19358,55 a & 17163,77 a \\
\hline Tratamento do solo & Solarização & Total/ha (kg) & Comercial/ha (kg) \\
\hline \multirow[t]{2}{*}{ Testemunha } & Solarizado & $4273,24 \mathrm{a}$ & 3341,55 a \\
\hline & Não solarizado & 3196,88 a & 2654,83 a \\
\hline \multirow[t]{2}{*}{ Uréia } & Solarizado & $5631,47 \mathrm{a}$ & 4974,59 a \\
\hline & Não solarizado & $1679,00 \mathrm{a}$ & 1300,74 a \\
\hline \multirow[t]{2}{*}{ Cama } & Solarizado & $15208,91 \mathrm{a}$ & 13863,29 a \\
\hline & Não solarizado & $1576,03 \quad b$ & 917,21 \\
\hline \multirow[t]{2}{*}{ Brometo } & Solarizado & $15847,28 \mathrm{a}$ & $14015,77 \quad$ a \\
\hline & Não solarizado & 19358,55 a & $17163,77 \quad$ a \\
\hline
\end{tabular}

${ }^{1}$ Parcela $15 \mathrm{~m}^{2}$ com $6 \mathrm{~m}^{2}$ parcela útil; ${ }^{2}$ Comparações feitas dentro de cada subdivisão da tabela. Médias seguidas pela mesma letra não diferem significativamente pelo teste de Tukey 5\%, médias de 5 repetições; ${ }^{3}$ Espaçamento 0,8 x 0,35 cm, densidade de plantas 0,28 (35714,28 plantas/ha).

bela 1). Embora não significativa estatísticamente, a solarização isoladamente permitiu aumento de $30 \%$ na produção em relação à testemunha (Tabela 1). O uso do brometo de metila permitiu aumentos bastante significativos na produção, independente da solarização do solo, em média $450 \%$ em relação à testemunha. A solarização do solo associada à adição de cama de aves também permitiu aumentos significativos na produção, em cerca de $340 \%$ em relação à testemunha não solarizada (Tabela 1). Embora o brometo de metila associado ou não à solarização seja o único tratamento com efeito significativo na redução da incidência da murcha-bacteriana em batata, o uso da solarização associada à adição de cama de aves permitiu aumento de produção semelhante ao tratamento com brometo de metila. Os mecanismos pelos quais este tratamento permitiu produção semelhante às parcelas tratadas com brometo de metila precisam ser investigados. No presente trabalho, os grandes incrementos na produtividade propiciados pelo uso do brometo de metila e pela solarização associada à adição de cama de aves se referem a uma área altamente infestada com $R$. solanacearum, onde a incidência de murcha-bacteriana reduziu intensamente a produção nos tra- tamentos testemunha, enfatizando o possível efeito positivo das técnicas sobre a produtivade da cultura mesmo quando realizadas nesta época do ano. Nenhum dos tratamentos, no entanto, eliminou completamente o patógeno do solo. Este resultado é esperado considerando o efeito não biocida da solarização e biofumigação, a alta infestação da área com $R$. solanacearum, a época não recomendada em que foi realizada a solarização (outono) e as características de sobrevivência da bactéria no solo. McCarter et al. (1976), ao estudarem a distribuição vertical de $R$. solanacearum em vários tipos de solos, verificaram que a população bacteriana na camada de 0 a $15 \mathrm{~cm}$ foi menor que na camada de 15 a $30 \mathrm{~cm}$, o que foi atribuído à maior variabilidade da umidade do solo na camada superficial. Também Okabe (1971) e Graham \& Lloyd (1979) mostraram que este patógeno sobreviveu melhor a maiores profundidades do que na camada mais superficial do solo, sugerindo que bolsões de solo infestados favorecem a sobreviência da bactéria por maior tempo. Portanto, as elevações de temperatura provocadas pela solarização têm efeito limitado sobre o inóculo presente no solo. A associação com outros mecanismos envolvidos na 


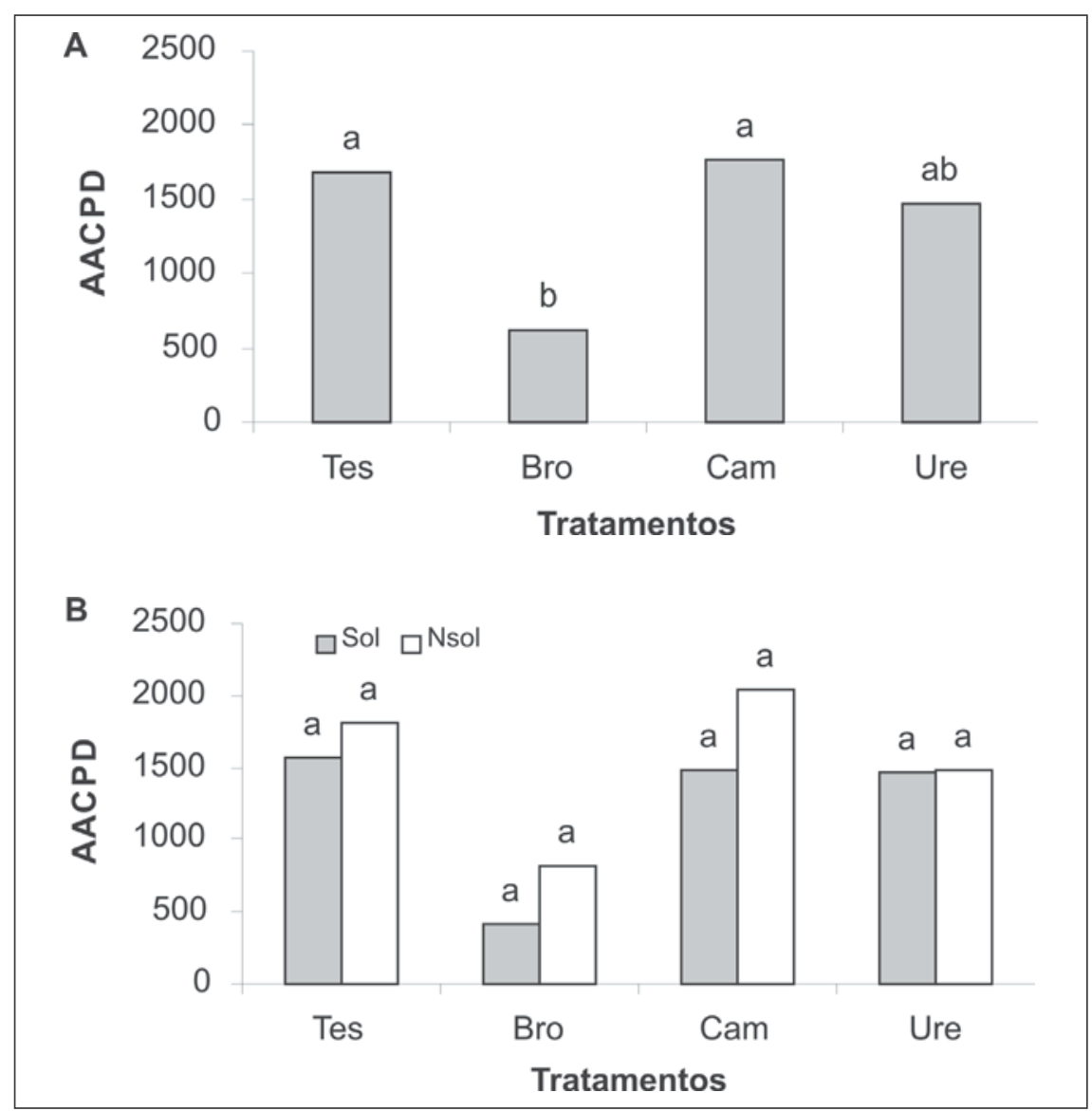

Figura 1. Área abaixo da curva de progresso da murcha-bacteriana da batata. Brasília, Embrapa Hortaliças, 2004.

Barras com as mesmas letras não diferem significativamente pelo teste de Tukey $5 \%$. A. Médias dos tratamentos de solo. B. Médias dos tratamentos solarizados e não solarizados. Sol = tratamentos solarizados; $\mathrm{Nsol}=$ não solarizados; Tes $=$ testemunha; Bro = brometo; Cam $=$ cama de aves; Ure $=$ ureia.

solarização, como alterações na flora microbiana e outras medidas de controle como a biofumigação, podem explicar os resultados obtidos. Durante a solarização, nas camadas mais profundas, somente temperaturas subletais são obtidas. Apesar do calor ser um importante fator para o controle dos fitopatógenos, não é o único mecanismo envolvido no método. Processos microbianos induzidos pela solarização podem contribuir para o controle, pois o aquecimento atua sobre a microbiota do solo em geral (Ghini, 1997).

O resultado obtido com a solarização, associada ao uso da cama de aves neste trabalho, evidencia o efeito de fatores relacionados não apenas à elevação de temperatura, mas destaca a possibilidade do uso destes métodos em conjunto. Os resultados apresentados evidenciaram o efeito significativo da solarização do solo associada à adição de cama de aves na produção de tubérculos de batata em área infestada com $R$. solanacearum e a necessidade de um estudo mais detalhado sobre os processos que ocorrem no solo como resultado destes tratamentos.

\section{LITERATURA CITADA}

BAPTISTA MJ; LOPES CA; SOUZA RB. 2004. Efeito da solarização e biofumigação na incidência de murcha-bacteriana em tomate cultivado em condições de campo. Horticultura Brasileira, Brasília 22: 424, suplemento 2. CD-Rom. Trabalho apresentado no $44^{\circ}$ Congresso Brasileiro de Olericultura. COCA DM. 2001. Efeito da adubação orgânica em batata (Solanum tuberosum L.) cultivada em solo infestado com Ralstonia solanacearum Biovar 1. 57 f. Dissertação, Universidade de Brasília, Brasília.

DAVIS JR; SORENSEN LH. 1986. Influence of soil solarization at moderate temperatures on potato genotypes with differing resistance to Verticillium dahliae. Phytopathology 76: 1021-1026.

ELADY; KATANJ, CHET I. 1980. Physical, biological and chemical control integrated for soilborne diseases in potatoes. Phytopathology 70: 418-422.

EMBRAPA HORTALIÇAS. Dados meteorológicos da Estação Agroclimática do CNPH. Disponível em: $<$ http://www.cnph.embrapa.br/cnph/consulta.html $>$. Acesso em:11 mar. 2005.
FONTES PCR. 1999. Sugestões de adubação para a diferentes culturas em Minas Gerais - Batata. In: RIBEIRO AC; GUIMARÃES PTG; ALVAREZ VH. (Ed.) Recomendações para o uso de corretivos e fertilizantes em Minas Gerais - $5^{a}$ aproximação. Viçosa, p.179.

GHINI R. 1997. Desinfestação do solo com o uso de energia solar: solarização e coletor solar. Jaguariúna: Embrapa - CNPMA, 29 p.

GHINI R. 2001. Alternativas para substituir o brometo de metila na agricultura. Summa Phytopathologica 27: 162.

GHINI R; PATRÍCIO FRA; SOUZA MD; SINIGAGLIA C; BARROS BC; LOPES MEBM; TESSARIOLI NETO J; CANTARELLA H. 2003. Efeito da solarização do solo sobre propriedades físicas, químicas e biológicas dos solos. Revista Brasileira de Ciência do Solo 27: 71-19.

GHINI R; SHOENMAKER IAS; BETTIOL W. 2002. Solarização do solo e incorporação de fontes de matéria orgânica no controle de Pythium spp. Pesquisa Agropecuária Brasileira 37: 1253-1261 GRAHAM J; LLOYD AB. 1979. Survival of potato strain (race 3) of Pseudomonas solanacearum in the deeper soil layers. Australian Journal of Agricultural Research 30: 489-496.

KATAN J. 1980. Solar Pasteurization of Soils for Disease Control: Status and Prospects. Plant Disease 64: 450-454.

LAZAROVITS G. 2001. Management of soilborne plant pathogens with organic soil amendments: a disease control strategy salvaged from the past. Canadian Journal of Plant Pathology 23: 1-7.

LOPES CA; QUEZADO-SOARES AM. 2000. Doenças causadas por bactérias em batata. In: ZAMBOLIM L; VALE FXR; COSTAH. (Ed.). Controle de Doenças de Plantas - Hortaliças, p. 209-249. MAPA - Ministério da Agricultura, Pecuária e Abastecimento. Instrução Normativa $n^{\circ} 1$, setembro/2002. Disponível em: <http:// www.ambiente.sp.gov.br/prozonesp/instrução normativa 01.pdf> .Acesso em: 11 jan. 2006.

MAY-DE MIO LL; GHINI R; KIMATI H. 2002. Solarização para controle de Phytophthora parasitica em mudas de Citros. Fitopatologia Brasileira 27: 254-258.

McCARTER SM; DUKES PD; JAWORSKI CA. 1969. Vertical distribution of Pseudomonas solanacearum in several soils. Phytopathology 59: 1675-1677.

MICHEL VV; MEW TW. 1998. Effect of a soil amendment on the survival of Ralstonia solanacearum in different soils. Phytopathology 88: 300-305.

OKABE N. 1971. Population changes of Pseudomonas solanacearum and soil microrganisms inartificially infested natural soils. Review of Plant Protection Research 4: 105-108. SCHONFELD AJ; GELSOMINOB A; VAN OVERBEIKC LS; GORISSENC A; SMALLAAK; VANELSAS JD. 2003. Effects of compost addition and simulated solarization on the fate of Ralstonia solanacearum biovar 2 and indigenous bacteria in soil. FEMS Microbiology Ecology 43: 63-74

SINIGAGLIA C; PATRICIO FRA; GHINI R; MALAVOLTA VMA; TESSARIOLI NETO J; FREITAS SS. 2001. Controle de Sclerotinia minor, Rhizoctonia solani e plantas daninhas em alface pela solarização do solo e sua integração com controle químico. Summa Phytopathologica 27: 229-235.

SOUZA NL. 1994. Solarização do solo. Summa Phytopathologica 20: 3-15.

STAPLETON JJ. 2000. Soil solarization in various agricultural production systems. Crop Protection 19: $837-841$. 